\title{
The impact of training of peer educator on sexual and reproductive health: An interventional study
}

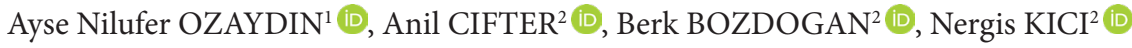 \\ ${ }^{1}$ Department of Public Health, School of Medicine, Marmara University, Maltepe, Istanbul, Turkey. \\ ${ }^{2}$ School of Medicine, Marmara University, Maltepe, Istanbul, Turkey. \\ Corresponding Author: Ayse Nilufer OZAYDIN \\ E-mail: nozaydin@gmail.com
}

Submitted: $11.01 .2020 \quad$ Accepted: 17.04 .2020

\section{ABSTRACT}

Objectives: This study aims to reveal the knowledge and attitude change that a well-structured sexual and reproductive health (SRH) peer educator training creates in volunteer preclinical students from Marmara University School of Medicine.

Materials and Methods: Participants ( $\mathrm{n}=29$ ) were given 28 hours of training on 13 subjects by professionals. Those who attended and completed all sessions were certified as "peer educator" (Group 1,n=12). Group $2(n=17)$ participated only in the first 8 sessions. SRH attitudes and knowledge levels of participants were evaluated. Data was analysed in SPSS-11.0 programme.

Results: Females constitute $51.7 \%$ of the participants. All participants had the similar level of "egalitarian" point of view (p:0.859). SRH final attitude score of Group 1 was higher than preliminary attitude score (p:0.008) and SRH final attitude score of Group 2 (p:0.033). The mean SRH knowledge score of Group 1 was 38.3 \pm 4.65 , while that of Group 2 was $26.76 \pm 4.16$ (p:0.0001).

Conclusion: It has been shown that a well-structured peer educator training can increase the knowledge of volunteer medical students and make a positive attitude change. After the implementation of the "Health Transformation Programme" in Turkey, adolescents were ignored. So, with peer educator trainings, trained educators will be able to help those adolescents and offer unprejudiced and egalitarian services to their patients when they become physicians.

Keywords: Adolescent health, Attitude, Gender roles, Contraception

\section{INTRODUCTION}

Adolescence is both an important period in which new behaviours are acquired and the most effective intervention period in preventing adult risk taking behaviours [1]. Even though, the adolescent group, which constitutes approximately $17 \%$ of the world population, is the most vulnerable group in terms of sexual and reproductive health (SRH), they are unable to access and make demand for health services [2].

Although, the lack of information about SRH of adolescents has been recognized in 1994 and studies have begun, the problem remains today [3]. According to a study done with 141 students studying in a public high school during the 2016-2017 academic year in Istanbul, the level of students' SRH knowledge was found to be inadequate [4]. A similar situation has been identified in medical schools too. A study, conducted in 2014 with 857 students from Trakya University School of Medicine in Edirne, Turkey has shown that only $23.5 \%$ of first and second-year students, and $23.1 \%$ of third and fourth-year students correctly knew how to prevent sexually transmitted infections (STI) [5].
Because most of the young people acquire knowledge and behaviour from their friends and share these with their friends, it has been shown that reaching young people with their own peers is a more appropriate approach [6]. Peer education is shown as one of the most effective educational tools to reach adolescents [7].

Peer education is an approach that aims sharing of information, skill or attitude between people who are involved in the same group in terms of age, sex, education or status [8]. Young people are more likely to internalize messages and thus, change their attitude and behaviour when they think that the person, they are talking to is like them and carries the same concerns [9]. Peer education is one of the most effective methods frequently used for SRH, which is one of the most difficult subjects for young people to talk about.

Well-structured SRH peer education has been shown to create changes in knowledge, attitudes and behaviour in both peer educators (PE) and peers/students trained by PE [10]. It has

How to cite this article: Ozaydin AN, Cifter A, Bozdogan B, Kici N. The impact of training of peer educator on sexual and reproductive health: An interventional study. Marmara Med J 2020;33: 75-82 doi: 10.5472/marumj. 738403 
also been shown that the self-esteem of students who receive peer educator training has increased, and their leadership and communication skills are improved [11].

In this study, it is aimed to show that a well-structured SRH peer educator training programme changes the knowledge and the attitude of voluntary medical school students.

\section{MATERIALS and METHODS}

This is an interventional study. The intervention is the training given to the students.

For the study, the ethics permission was obtained from Marmara University School of Medicine Clinical Research Ethics Committee (with the protocol number 09.2017.255 and the date 7 April 2017). All participants were informed and their consent was obtained.
The population of the study was the pre-clinical students who study at Marmara University School of Medicine (MUSM). After presented the project in social media, applications have been accepted with an online form for a period of two weeks $(n=35)$. In this project, those who attended and successfully completed the 13 sessions (28 hours) were certified as "peer educator".

The purpose of the training is to ensure that volunteer students can inform their peers at SRH issues and support them in solving their SRH problems. As well as sessions that provided information on basic SRH subjects, sessions aimed at providing a positive change of attitude in the areas related to SRH were also given during the training. To communicate positively with their peers and to be able to transfer their knowledge in effective ways, communication and presentation skills and contraceptive counselling were also included in the training programme.

Table I presents the curriculum of the training programme (28 hours on 13 topics).

Table I. Curriculum of training programme

\section{No}

Duration(hours)

a. Introduction and SRH Rights

1 Introduction to Sexual and Reproductive Health: Basic Concepts

2 Sexual and Reproductive Health Rights

\section{b. Breast Cancer} Breast Cancer Awareness and Breast Self-Examination

c. HIV / AIDS and STI

$4 \quad$ Sexually Transmitted Infections and The Ways of Prevention

\section{d. Basic Concepts in SRH I}

5

6 Sociological Aspect of HIV/AIDS and Stigmatisation

$7 \quad$ LGBTI + Identities and Misunderstandings

8 Litigation of LGBT Individuals and Legal Discriminations

e. Basic Concepts in SRH II

9 Sexual and Reproductive Health Status of Youth in Turke

$10 \quad$ Gender

$11 \quad$ Male Sexual Health Issues

12 Contraceptive Methods, Emergency Contraception

13 Communication and Presentation Skills

TOTAL
1

6

3

3

1

2

2

2

1

1

3

2

28 


\section{Intervention Event (Training)}

\section{a. Introduction to SRH and SRH Rights}

The purpose of the first part was to briefly introduce the anatomy and physiology of male and female reproductive systems to the participants.

In the second half of the day, the legal status of SRH rights in the World and in Turkey was explained with a presentation. Then to consolidate this knowledge, a case study was applied.

\section{b. Breast Cancer}

The aim was to teach "breast self-examination" skills, which is a breast cancer awareness and preventive action, considering the age group of the $\mathrm{PE}$ and peers.

\section{c. HIV/AIDS and STI}

Together with informing about STI and HIV/AIDS, training has been provided for developing sensitivity and attaining a positive attitude. In addition, the use of male and female condoms on the models was demonstrated.

\section{d. Basic Concepts in SRH I}

In order for youth to be able to recognise and express their own norms and values regarding the sexuality; "SRH Social Norms" topic has been mentioned.

In the next session, the social aspect of HIV/AIDS and the acts of stigmatisation in Turkey were discussed. In the following sessions; description of lesbian, gay, bisexual, transgender and intersex (LGBTI+) identities, the prejudices and attitudes these people encounter in the world; the problems encountered in the justice system by the transgender individuals in Turkey were explained and the proposed solutions were discussed.

\section{e. Basic Concepts in SRH II}

In the first session, nationwide research findings on adolescents in Turkey were shared, and local adolescent problems were discussed. The concept of gender on health and social life was generally mentioned.

In the third session, men's sexuality and the most common sexual health problems specific to adolescents were discussed.

A long session about contraception was held to prevent adolescent pregnancies and STIs.

During the last session of the day and the year, a session about communication and presentation skills was held to enable peers to transfer their knowledge and skills effectively and successfully to their friends.

The data related to the study was obtained with the information forms taken at the beginning of the training and after. The study was evaluated using two kinds of data that was gathered from the participants: their socio-demographic standing, and their SRH knowledge, attitude and ideas about cultural gender roles. The latter was gathered using standard measures.

\section{Assessment of Training, Data Collection Tools}

The first data was collected with a form for socio-demographicinformation, the gender roles attitude scale (GRAS,ZeynelogluTerzioglu,2011) and the SRH attitudes scale (SRHAS). After the training, data was collected for evaluating the knowledge of SRH and SRHAS.The evaluation of the training is based on four-stage "Kirkpatrick Model” [12].

\section{Reaction}

At the end of each session, feedbacks were gathered from the participants anonymously and these feedbacks were put into practice in the further stages of the training and at the end of the training. Feedbacks were taken using the "Course Evaluation Form".

\section{Learning}

Participants' SRH knowledge was assessed by a questionnaire consisting 15 questions. There were 13 multiple choice and 2 true-false questions. Each of correct answer was given one point; 4 points for physiology of reproductive system, 3 points for STI, 12 points for correct condom usage and 29 points for contraceptive methods (max: 48 points, min:0 points).

Participants' general SRH attitudes were assessed twice with "SRH Attitude Assessment Scale [13]" before and after training. The scale includes 30 statements with five Likert-type scale responses. Answers to questions 1-7, 10-14, 18, 21-24 are a linear scale between strongly disagree: 1 and, strongly agree:5, on the other hand answers to questions 8-9, 15-17, 19-20, 25-30 are a linear scale between strongly agree: 1 and strongly disagree:5 (max:150, min:30). The scores obtained from each question are added to obtain a "total attitude score".

The "Gender Roles Attitude Scale [14]" was used to assess participants' gender attitudes. The scale includes five subsections with 38 items. The subsections consist of egalitarian gender role", "female gender role", "gender role in marriage", "traditional gender role", and "male gender role". Responses were collected on a five-point Likert-type scale. The answers were scored as 5 points for 'completely agree', 4 points for 'agree', 3 points for 'undecided', 2 points for 'disagree', and 1 point for 'absolutely disagree. The scores obtained from each question were added to obtain the "total score" (max:190, min:38). If the total score is less than 95, it is interpreted as having "traditional attitude" and if it is greater than 95, it is interpreted as having "egalitarian attitude".

\section{Statistical Analysis}

The collected data was evaluated in the SPSS 11.0 programme and analysed with normality tests, Spearman/Pearson correlation, Mann-Whitney-U, Student-T, and Sign tests. The statistical significance level was considered as $\mathrm{p}<0.05$. 


\section{RESULTS}

Twelve of the 29 volunteer students who participated in 13 different sessions, fully participated in all the trainings and after being successful in evaluation, completed the training as "SRH Peer Educator (Group 1)". Seventeen students only participated in the first eight sessions of 13 sessions and were not certified as PE (Group 2).

Females constituted $51.7 \%$ of the participants $(n=15)$. The mean age of the participants was 20.31 \pm 1.03 (median:20.0, min:19, max:23). Distribution of participants' demographic information by groups is given in Table II.

According to the GRAS, all participants had the same level of "egalitarian" attitude (mean:173.6 \pm 14.0 , median:177.0, min:144.0 max:190.0) (p:0.859). Mean SRHAS score of the participants $(n=29)$ was $131.58 \pm 13.42$ (median:135.0, min:108, max:150) before the SRH training, and was 138.72 \pm 11.59 (median:143.0, min:108, max:150) after it (p:0.001).

The mean score of participants' SRH Knowledge Scale was 31.55 \pm 7.21 (median:30.0, min:19, max:44).

Table II. Distribution of socio-demographic characteristics of Group 1 and 2

\begin{tabular}{|c|c|c|c|c|c|c|c|}
\hline Socio-demographic characteristics & & & & & & & $\mathrm{p}$ \\
\hline & n & $\%$ & n & $\%$ & $\mathbf{n}$ & $\%$ & \\
\hline Sex & & & & & & & \\
\hline Female & 6 & 50.0 & 9 & 52.9 & 15 & 51.7 & \\
\hline Male & 6 & 50.0 & 8 & 47.1 & 14 & 48.7 & 1.000 \\
\hline
\end{tabular}

\begin{tabular}{|c|c|c|c|c|c|c|c|}
\hline $19-20$ & 9 & 75.0 & 10 & 58.8 & 19 & 65.5 & \\
\hline$\geq 21$ & 3 & 25.0 & 7 & 41.2 & 10 & 34.5 & 0.449 \\
\hline
\end{tabular}

Education Level of Mothers

$\begin{array}{cccccccc}\text { High school and below } & 6 & 50.0 & 7 & 41.2 & 13 & 44.8 & \\ \text { University and above } & 6 & 50.0 & 10 & 58.8 & 16 & 55.2 & 0.716\end{array}$

Education Level of Fathers

High school and below
University and above

8

33.3

66.7

12

Monthly Family Income

$\leq 6000$ TLY
$>6000$ TLY

5

7

12

5
29.4

70.6
9

20

$70.6 \quad 19$

29.4
19

10
31.0

69.0

Living with parents

Yes

$10 \quad 83.3$

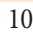

7

\section{8}

41.2
65.5

34.5

0.694

Self-evaluation of Health Status

Very Healthy/Healthy
Uncertain/Sick/Very sick

Total

On 05.06.2017 the rate of U.S. Dollar to Turkish Lira (TYL) $=3.50$

11

1

12 100.0 17 100.0 29

69.0

31.0 0.234 
Table III presents the distribution of the scores of Group 1 $(\mathrm{n}=12)$ and Group $2(\mathrm{n}=17)$.

Group 1's SRH final attitude assessment score (median:146.5) was higher than preliminary attitude assessment score (median:139.5) (p:0.008). A positive, strong, and statistically significant correlation was found between these scores ( $r: 0.746$, p:0.005).


than preliminary attitude assessment score (127.4 \pm 13.4$)$ (p:0.018). A positive, moderately strong and statistically significant correlation was found between these scores (r:0.601, p:0.011).

Table III. Overall score statistics for both groups

\begin{tabular}{|c|c|c|c|c|c|c|c|}
\hline Assessment Type & $\mathbf{n}$ & Mean & $\begin{array}{l}\text { Standard } \\
\text { Deviation }\end{array}$ & Median & Min & Max & p \\
\hline \multirow{2}{*}{ Gender Roles Attitude Score } & $12^{\dagger}$ & 173.8 & 10.7 & 171.5 & 160.0 & 190.0 & \multirow{2}{*}{0.859} \\
\hline & $17^{\ddagger}$ & 173.5 & 16.3 & 177.0 & 144.0 & 190.0 & \\
\hline \multirow{2}{*}{ SRH Preliminary Assessment Score } & 12 & 137.9 & 11.3 & 139.5 & 115.0 & 150.0 & \multirow{2}{*}{0.041} \\
\hline & 17 & 127.4 & 13.4 & 127.0 & 108.0 & 149.0 & \\
\hline \multirow{2}{*}{ SRH Final Assessment Score } & 12 & 144.2 & 7.1 & 146.5 & 127.0 & 150.0 & \multirow{2}{*}{0.033} \\
\hline & 17 & 134.9 & 12.7 & 137.0 & 108.0 & 149.0 & \\
\hline \multirow{2}{*}{ SRH Knowledge Score } & 12 & 38.2 & 4.7 & 40.0 & 29.0 & 44.0 & \multirow{2}{*}{0.0001} \\
\hline & 17 & 26.8 & 4.2 & 27.0 & 19.0 & 34.0 & \\
\hline
\end{tabular}

:Group $1(\mathrm{n}=12),{ }^{\ddagger}$ : Group $2(\mathrm{n}=17)$ SRH: sexual and reproductive health

The mean SRH knowledge score of Group 1 was 38.3 \pm 4.65 , while that of Group 2 was $26.76 \pm 4.16$ (p:0.0001). The knowledge scores of Group 1 were found to be higher than the scores of Group 2 in the subjects of STI (p:0.043), general contraception (p:0.0001), emergency contraception (EC) (p:0.0001) and correct condom usage (p:0.015). The knowledge about physiology of reproductive system was similar in both groups (p:0.028). (Table IV).

To the question that asks for other emergency contraceptive methods that can replace hormonal contraceptives, while $83.3 \%$ of Group 1 gave the answer as contains the copper-bearing intrauterine device (Cu-IUD), only \%11.7 of Group 2 chose this answer (p:0.0001).

Table IV. Distribution of SRH knowledge scores according to groups

\begin{tabular}{|c|c|c|c|c|c|c|c|}
\hline SRH Knowledge Scale & $\mathbf{n}$ & Mean & $\begin{array}{l}\text { Standard } \\
\text { Deviation }\end{array}$ & Median & Min & Max & p \\
\hline \multirow{2}{*}{$\begin{array}{l}\text { Reproductive System Physiology Knowledge } \\
\text { Score }\end{array}$} & $12^{\dagger}$ & 3.8 & 0.6 & 4.0 & 2.0 & 4.0 & \multirow{2}{*}{0.088} \\
\hline & $17^{\ddagger}$ & 3.6 & 0.56 & 4.0 & 3.0 & 4.0 & \\
\hline \multirow{2}{*}{ STI Knowledge Score } & 12 & 3.0 & 0.0 & 3.0 & 3.0 & 3.0 & \multirow{2}{*}{0.043} \\
\hline & 17 & 2.5 & 0.9 & 3.0 & 0.0 & 3.0 & \\
\hline \multirow{2}{*}{ General Contraception Knowledge Score } & 12 & 11.2 & 2.0 & 11.0 & 7.0 & 13.0 & \multirow{2}{*}{0.0001} \\
\hline & 17 & 6.4 & 1.5 & 6.0 & 4.0 & 9.0 & \\
\hline \multirow{2}{*}{ Emergency Contraception Knowledge Score } & 12 & 9.0 & 2.3 & 9.0 & 4.0 & 12.0 & \multirow{2}{*}{0.0001} \\
\hline & 17 & 4.2 & 1.88 & 4.0 & 1.0 & 8.0 & \\
\hline \multirow[b]{2}{*}{ Correct Condom Usage Knowledge Score } & 12 & 11.3 & 1.2 & 12.0 & 9.0 & 12.0 & \multirow[b]{2}{*}{0.015} \\
\hline & 17 & 10.1 & 1.5 & 10.0 & 7.0 & 12.0 & \\
\hline
\end{tabular}

:Group $1(\mathrm{n}=12)$, : Group 2 ( $\mathrm{n}=17)$ SRH: sexual and reproductive health, STI: sexually transmitted infections

\section{DISCUSSION}

In this study, it was aimed to show the impact of a well-structured peer educator training on changing the SRH knowledge and the attitude of voluntary medical school students, who want to provide unprejudiced and egalitarian service to their patients. Also, authors would like to suggest a model curriculum to researchers that are interested in SRH matters.

According to the Report of the International Conference on Population and Development (ICPD), adolescence is defined 
as one of the important age groups in SRH [15]. It is both the riskiest group and the group in which positive behaviours begin to be acquired in the field of SRH. Also, they are the group that can be affected most positively by interventions. To increase the accessibility and quality of SRH services for adolescents in Turkey, which were never offered before 1994, and to ensure the use of these services, the European Union supported 55 million Euro budgeted the Reproductive Health Programme was implemented in Turkey as one of the signatories of the ICPD. However, in 2003, when the "Health Transformation Programme" was implemented by making radical changes in the health care system in Turkey, Youth Friendly Reproductive Health Centres were not included in the new organizational chart, so the situation returned to what it was before 1994 [16, 17].

After the inception of the programme in 1994, it was decided that all students should be given 40 minutes of SRH training in schools until end of the 11th year of basic education. For this purpose, training materials were prepared [18], high school teachers were trained and school trainings were started. Parallel to the implementation of the "Health Transformation Programme", school curricula changed and the SRH trainings came to an end.

A great deal of experience and knowledge was gained through implementation of the programme. But with the change of the health system, adolescents were once more ignored again. To meet the needs of the information source and counselling with "peer education", which has proven its effectiveness, it was aimed to do SRH peer educator training by choosing volunteers from the first - and second-year students of MUSM in 2016-2017 education period. Twenty-nine people participated in trainings on 13 different subjects that lasted 28 hours in total. Twelve of them have participated in all trainings and have been certified as "Peer Educator" by getting a high grade in the knowledge evaluation. To meet the existing information and consulting needs, this study will not be left as a project only. New peer educator trainings, plans and follow-ups of PE's trainings are planned in the future to ensure sustainability. Briefly, to be able to train $12 \mathrm{PE}$ at the end of the study, which was planned and maintained with totally voluntary participants and trainers to meet the need emerging with the new health system, is one of the strongest aspects of our study. And to be able to plan this in 2016 while realizing that different projects should be carried out for the provision of SRH needs and rights for adolescents as Chandra-Mouli et al [19] stated in 2017 is another strong point of ours. Up to now, authors could reach few articles in English similar to this study's topic.

The trainings in this project were inevitably done in the time periods outside of school hours and/or at the weekend, as the participants were full-time university students. Although, this research has an important limitation that $100 \%$ participation in the trainings in the programme could not be achieved, the sensitivity of the subjects and the participation on the basis of volunteering did not make this possible. The training programme has been planned and implemented together with educators and PE candidates. It was aimed to create a model curriculum for people who are interested in SRH. And those who aim to organize training can put into practice this curriculum by adapting subjects and durations according to their own goals. Moreover, the long-term effects of peer education were not among the aims of this article. We recommend that the results of the research should be interpreted and evaluated according to this perspective. And future studies should be planned to evaluate the issue.

In our study, the socio-demographic characteristics of Group 1 and Group 2 were similar, such as sex, age, parent educational status, income level, place of residence, and thoughts on their own health status. It was determined that the participants had an egalitarian gender perception. We think that this may be due to the fact that our participants are a homogeneous group of volunteers and motivated people who are interested in SRH, studying at the same school and are in the same age group. In another study conducted at MUSM with 394 preclinical students on the same dates as our research, it was found that most of the students had an "egalitarian attitude" [20]. In an earlier research conducted with 507 students from Erzurum Atatürk University (2010-2011), health science students were found to be more egalitarian in their gender attitudes than the rest [21]. The fact that our participants who will serve in the healthcare field in future have "egalitarian gender" perception and will be able to provide services without gender discrimination made us happy in terms of showing that we reached one of the objectives of our study.

Although, the gender attitudes of Group 1 and Group 2 were "equal" and similar to each other, Group 1's "SRH attitudes", which were assessed on a different scale, were more positive than Group 2 before and after the training. However, both groups were able to make positive changes in SRH attitude. The reason for the positive development in both groups may be the attitude-focused nature of the first 8 education subjects that both groups participated in. Similar to our findings, in a study conducted in Ohio and Kentucky in the USA in 1995-96, which is one of the few studies investigating the effects of peer educator training on educators, an increase in attitudes of PE was found with HIV and alcohol prevention based peer educator training done with 8459 th grade students from 17 high schools. But the data reported that they could not achieve meaningful results due to problems with collecting data [22].

It was determined that Group 1, whose knowledge levels were significantly increased with training, had better SRH knowledge than Group 2. Group 1 was better in the subjects of STI, general and EC and condom use because the last sessions of the training focused on SRH knowledge. The reason that there was no difference in knowledge about the physiology of the reproductive system may be due to the fact that reproductive system physiology was mentioned during the first session of the training which both groups attended. Also, the vast majority of Group 1 were aware of the fact that Cu-IUD could be used for emergency contraception such as hormonal contraceptive methods, but the vast majority of Group 2 did not. Parallel to our results, an increase in HIV/AIDS and STI knowledge levels has been shown in a peer educator training programme conducted 
with 30 university students in the USA in 1999 [23]. In another peer educator training programme with 70 university students at Stanford University, a positive change in SRH norms and STI knowledge level was shown [24].

Young people who are inadequately informed about SRH may be prone to unsafe behaviour and may be at risk. With this type of trainings, risky behaviours can be avoided by increasing SRH knowledge [25]. It is also possible to break down the medical barrier in front of adolescents which is an issue that Chandra-Mouli et al., also emphasize [19], by providing positive attitude development as it is in our educational programme and understanding the sexual and reproductive rights, besides increasing the knowledge of young people and especially those studying in the medical school.

In this study, we showed that the volunteers who participated in the training programme had increased knowledge of SRH and their attitudes improved in a positive way. We completed the first step of our project in SRH. The next step is to ensure that $\mathrm{PE}$ have a positive attitude and behaviour by reaching out to peers and increasing their knowledge. For this reason, we aim to create knowledge and attitude change in the peers by providing information transfer in the most appropriate way in our future work. As researchers, we need to pay attention to the fact that the actual effects of the studies that start with the same goal do not reach the desired level $[26,27]$. So, we will consider the problems that occurred in the studies done before, and plan the training and the role of PE [28]. We hope that problems will end in this way, and not only the PE but also those who they will reach out to, can also benefit from our study [4].

In conclusion, our research has shown that a well-structured peer educator training programme can increase the knowledge of medical students who volunteer to become PE and can result in a positive attitude change. Trained PEs will be able to help themselves and the people they reach, to be healthy in the field of $\mathrm{SRH}$ with the achievements they received. Moreover, when they become physicians, they will make a positive contribution to patients for life, and offer unprejudiced and egalitarian services.

We tried to contribute to the SRH training with our local trainers. And we will continue to work until the day that provision of easily accessible and young friendly SRH counselling and services to the adolescents without prejudice will take place in the new health system.

\section{Acknowledgement}

The authors would like to thank all voluntary trainers, Assoc. Prof. Dr. Gürkan SERT, Canberk Noyan HARMANCI, Dr. Seven KAPTAN, Atty. Rozerin Seda KIP and students for their participation in this project. Also, special thanks to Organisation of Patients' and Patients' Relatives Rights (HAYAD/Turkey) for their supports.

\section{Compliance with Ethical Standards}

Ethical Approval: This study was approved by Marmara University School of Medicine Clinical Research Ethics
Committee (with the protocol number 09.2017.255 and the date 7 April 2017).

Funding: The study was supported by the Organisation of Patients' and Patients' Relatives Rights (HAYAD/Turkey).

Conflict of Interest: The authors declare that they have no conflict of interest.

Informed Consent: A written informed consent was obtained from each participant.

Author Contributions: Concept - ANO, AC, BB, NK; Design ANO, AC, BB, NK; Supervision - ANO, AC, BB, NK Materials - ANO, AC, BB, NK; Data Collection and/or Processing - AC, $\mathrm{BB}, \mathrm{NK}$; Analysis and/or Interpretation - ANO, AC, BB, NK; Literature Search - ANO, AC, BB, NK; Writing Manuscript ANO, AC, BB, NK; Critical Review - ANO; Final Approval ANO, AC, BB, NK.

\section{REFERENCES}

[1] Kaya MC. Adolescent Health: Prevention and Early Detection. Istanbul: Medikal Akademi Yayıncılık, 2015; 11-20.

[2] World Health Organization. Adolescents: health risks and solutions web sites. Available at: http://www.who.int/ mediacentre/factsheets/fs345/en/. Accessed July 26, 2017.

[3] Chandra-Mouli V, Lane C, Wong S. What does not work in adolescent sexual and reproductive health: a review of evidence on interventions commonly accepted as best practices. Glob Health Sci Pract 2015; 3:333-40. doi: 10.9745/ GHSP-D-15-00126.

[4] Aslan S, Erdir B, Kabasakal I, et al. Sexual and reproductive health knowledge of the students in Sakip Sabanci High School. Paper presented at: 17th Marmara Student Congress; 2017 May 12-14; Istanbul, Turkey.

[5] Karatas N, Boncukcu E, Demirkiran H, et al. Knowledge level of Trakya University medical school students about sexually transmitted diseases. Turk Med Student J2014;1:65-8.

[6] Kirmizitoprak E, Simsek Z. The effect of peer-education on sexually transmitted diseases and safer sexual life knowledge and behaviour of young people. TAF Prev Med Bull 2011;10: 463-472. doi: 10.5455/pmb.201.011.19041649.

[7] Strange V, Forrest S, Oakley A. Peer-led sex educationcharacteristics of peer educators and their perceptions of the impact on them of participation in a peer education programme. Health Educ Res 2002;17:327-7.

[8] Karadag O, translator. Akran Eğitimi, Eğitimci Eğitimi Rehberi. [Peer Education, Educator Training Guide] Ankara (TR): Semih Ofset, 2004. Turkish.

[9] Maxwell KA. Friends: the role of peer influence across adolescent risk behaviors. J Youth Adolesc 2002;31:267-77. doi:https://doi.org/10.1023/A:101.549.3316865.

[10] Jennings JM, Howard S, Perotte CL. Effects of a school-based sexuality education program on peer educators: the Teen PEP model. Health Educ Res 2014;29:319-29. doi:10.1093/her/ cyt153. 
[11] Mason H. Peer education: Promoting healthy behaviors. Fact Sheet Advocates Youth. 2003; 3-4. Available at: https://www. advocatesforyouth.org/wp-content/uploads/storage//advfy/ documents/fspeered.pdf Accessed 13.11.2019.

[12] Kirkpatrick J, Kirkpatrick W. An Introduction to the New World Kirkpatrick Model. Newnan (GA): Kirkpatrick Partners, LLC, 2015.

[13] General Directorate of Mother and Child Health and Family Planning, Ministry of Health, Republic of Turkey. Gençlik Danışmanlık ve Sağlık Hizmet Merkezi Yönetici Rehberi [Counseling and health service center for young people: executive guide.] Ankara: Ministry of Health, 2007. Turkish.

[14] Zeyneloglu S. Attitudes of nursing students enrolled at universities in Ankara towards gender roles [dissertation]. Ankara, Turkey: Hacettepe University, 2008.

[15] United Nations. New York (NY): UN. Report of the International Conference on Population and Development, Cairo, 5-13 September 1994; 1995. Available at: https://www. unfpa.org/sites/default/files/event-pdf/icpd_eng_2.pdf. Accessed September 26, 2017.

[16] Atun R, Aydin S, Chakraborty S, et al. Universal health coverage in Turkey: enhancement of equity. Lancet 2013;382:65-99. doi: http://dx.doi.org/10.1016/S0140-6736(13)61051-X.

[17] Aktan AO, Pala K, Ilhan B. Health-care reform in Turkey: far from perfect. Lancet 2014;383:25-6. doi: http://dx.doi. org/10.1016/S0140-6736(13)62725-7.

[18] Cokar M, Nalbant H. Cinsel Sağlık Bilgileri Eğitimi-Öğretmen El Kitabı. [Sexual health informations-teacher handbook] Human Source Development Foundation. 2000. Turkish.

[19] Chandra-Mouli V, Parameshwar PS, Parry M, et al. A neverbefore opportunity to strengthen investment and action on adolescent contraception, and what we must do to make full use of it. Reproductive Health 2017;14:85. doi:10.1186/ s12978.017.0347-9.

[20] Pak T, Ulgen MA, Eren R, et al. Marmara University Faculty of Medicine 2016-2017 phase-1 students' attitudes toward gender roles. Poster session presented at Marmara Student Congress; 2017 May 12-14; Istanbul Turkey.
[21] Celik AS, Pasinlioglu T, Tan G, et al. Üniversite öğrencilerinin cinsiyet eşitliği tutumlarının belirlenmesi [Determination of university students' attitudes about gender equality]. F N Hem Derg 2013;21: 181-6. Turkish.

[22] Ebreo A, Feist-Price S, Siewe Y, et al. Effects of peer education on the peer educators in a school-based HIV prevention program: where should peer education research go from here? Health Educ Behav 2002;29:411-23. doi: 10.1177/109.019.810202900402.

[23] Badura AS, Millard M, Peluso EA, et al. Effects of peer education training on peer educators: Leadership, self-esteem, health knowledge, and health behaviors. J Coll Stud Dev 2000;41:471.

[24] Ehrhardt BL, Krumboltz JD, Koopman C. Training peer sexual health educators: Changes in knowledge, counseling selfefficacy, and sexual risk behavior. Am J Sex Educ 2008;2:3955. doi:http://dx.doi.org/10.1300/J455v02n01_04.

[25] Dag H , Donmez S , Sirin A , Kavlak O. Üniversite gençliğinin cinsel ve üreme sağlığıyla ilgili bilgi düzeyleri ve akran eğitimi. [University youth reproductive and sexual health knowledge and peer education] Journal of Anatolia Nursing and Health Sciences 2010;15:10-17. Turkish.

[26] Tolli MV. Effectiveness of peer education interventions for HIV prevention, adolescent pregnancy prevention and sexual health promotion for young people: a systematic review of European studies. Health Educ Res 2012;27:904-13. doi:https://doi.org/10.1093/her/cys055.

[27] Harden A, Oakley A, Oliver S. Peer-delivered health promotion for young people: a systematic review of different study designs. Health Educ J 2001;60:339-53. doi:10.1177/00 1.789.690106000406.

[28] Michielsen K, Beauclair R, Delva W, Roelens K, Van Rossem $\mathrm{R}$, Temmerman M. Effectiveness of a peerled HIV prevention intervention in secondary schools in Rwanda: results from a non-randomized controlled trial. BMC Public Health 2012;12:729. doi:10.1186/1471-2458-12-729. 